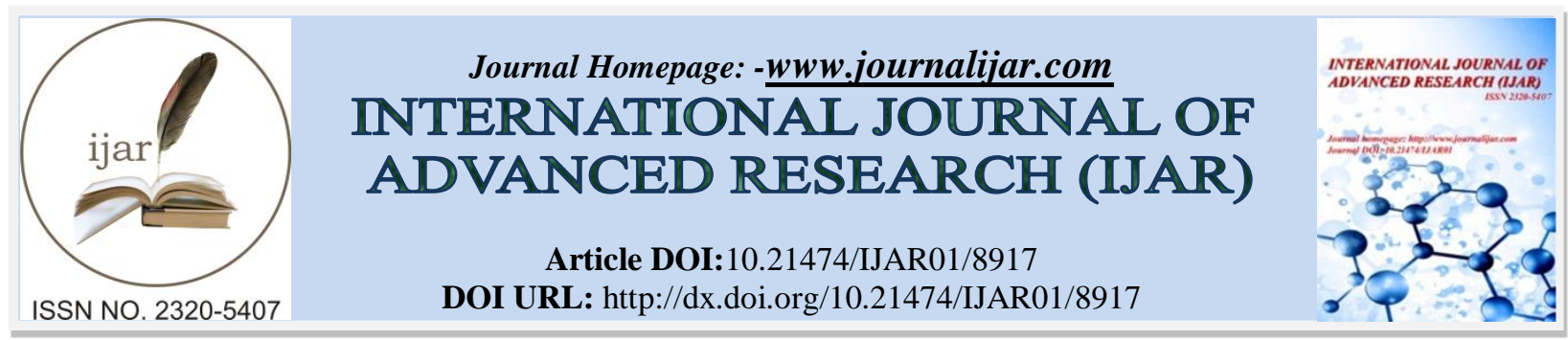

RESEARCH ARTICLE

\title{
APPLICATION OF DEMING'S CYCLE IN BENCHMARKING AND PERFORMANCE IN PUBLIC SECONDARY SCHOOLS IN KEIYO SUB-COUNTY, KENYA.
}

Edwin Kipsang' Kailong'.

Department of Quantitative Skills and Entrepreneurship Studies Moi University.

\section{Manuscript Info}

Manuscript History

Received: 20 February 2019

Final Accepted: 22 March 2019

Published: April 2019

Key words:-

Benchmarking, Deming's cycle, KCSE Performance.

\begin{abstract}
New generation of organizations have adopted management models and processes for measuring and managing organizational performance with collaboration and benchmarking being some of the approaches adopted by secondary schools in Kenya. This is geared at addressing the multiple expectations notably improved performance in the Kenya Certificate of Secondary Education (KCSE) examinations. The study aimed to examine the relationship between the application of Deming's Cycle model in benchmarking and performance of public secondary schools in KCSE in Keiyo Sub-County. The target population were school principals/deputy principals, directors of studies and head of departments from the 22 public secondary schools in Keiyo SubCounty. A sample of 7 schools was extracted using stratified sampling techniques. Data was collected using structured questionnaires and interview guides then analyzed was based on descriptive and inferential statistics. The study revealed that the processes of planning, data collection, data analysis and implementation of benchmarking reports are positively correlated with performance of schools in KCSE. The study recommends that schools can fully adopt the use of Deming's PDCA cycle model of benchmarking when carrying out benchmarking with other schools/institutions. I propose a similar study to be carried out on private secondary schools and also other sectors.
\end{abstract}

Copy Right, IJAR, 2019,. All rights reserved.

\section{Introduction:-}

The dynamic environment in the 21 st Century has necessitated the realignment of organisations to the new world order. The pace of change has increasingly created conditions for organizations to be more outward looking, market oriented and knowledge driven (Amunga, 2013). Jarrar \& Zairi, (2001) suggest that bench marking is a useful tool that can help businesses build strong capabilities, ensure an inward flow of ideas and establish true competitive gaps. Performance in secondary schools is measured basing on the end results of knowledge level or grades acquired by learners. Highly performing schools have been viewed to possess superior practices that enable them to achieve higher targets. This has motivated the interest of non-performing schools to adapt to the same practices so as to become competitive. The process of learning from the very best has resulted in benchmarking among schools.

Benchmarking is the process of identifying 'best practices' in relation to both products and services and the process by which those products are created and delivered. The search for 'best practice' may take place inside the industry 
or in another industry. The term "benchmarking" emerged when the idea took ground in United States during 1980s when Xerox, Ford and Motorola became the pioneers of benchmarking. Robert Camp, the logistics engineer who initiated Xerox's benchmarking program and who is generally regarded as the guru of the benchmarking movement, defines it as the search for industry best practices that lead to superior performance. The best example on benchmarking is Toyota Motors Corporation's Just-in-time system following the Ford's Motors Corporation's Justin-case system (Larisa \& Denisa, 2009; Magutu, 2011; Amunga, 2013). Benchmarking is also defined as a process where companies compare business processes and metrics with the expectation of determining what 'best-in-class' performance is and how 'best-in-class' performance has been achieved (Reid, 2008). It is a systematic management process that helps managers to search and monitor the best practices or processes (Prabir, 1995) and this search may not be limited to direct competitors alone but also to those from related industry (Pearce \& Robinson, 2005).

\section{Statement of the Problem}

In Kenya, the performance of schools has been determined by the terminal grade attained in the examination and the pressure for good results makes schools with lower grades to benchmark from schools that attain higher grades (Ongeri et al., 2014). In a study carried out by Ambula (2006) on the extent to which benchmarking has been established in secondary schools and whether it had led to improved performance in the Kenya Certificate of Secondary Education (KCSE) showed that, schools which used benchmarking had realized improved performance from 5.633 to 6.379. In Keiyo Sub-County, the existing information provided by the respective County Quality Assurance Officers is that several schools have participated in benchmarking but no follow-up reports have been presented and the correlation of the exercise with the level of performance in KCSE examination has never been made. The mean performance of the public secondary in KCSE from Keiyo Sub-county dropped from 6.188 in 2009 to 5.258 in 2013 with percentage rate of students obtaining university entry points also dropping by $6.1 \%$ (Keiyo Sub-county education report, 2014). Research has shown also that there are variations in the levels of improvement in school performance regarding to the use of benchmarking (Nyaoga et al. 2013; Ongeri et al. 2014). Amunga et al. 2013 identified differences in the mean scores of secondary schools in the Western Region (Kenya) as a result of collaboration and benchmarking resulted in an improvement of 0.742 in the mean score of schools during the five year period from 8.160 in 2007 to 8.902 in 2011 . The aim of this study was to examine the relationship between the application of Deming's Cycle model in benchmarking and the performance of public secondary schools in KCSE in Keiyo Sub-county, Kenya between 2009 to 2013 examinations period.

\section{The objectives of this study were to examine;}

1. The relationship between planning in benchmarking and the performance of public secondary schools in KCSE examination.

2. The relationship between data collection in benchmarking and the performance of public secondary schools in KCSE examination.

3. The relationship between data analysis in benchmarking and the performance of public secondary schools in KCSE examination.

4. The relationship between implementation of benchmarking reports and the performance of public secondary schools in KCSE examination.

\section{Limitations of the study}

This study applied the Deming's cycle model in benchmarking and was geographically restricted to public secondary schools in Keiyo Sub-County in Kenya

\section{Literature Review:-}

One of the essential elements of a successful benchmarking program is following a rigorous and structured process (American Productivity \& Quality Center, APQC, 1993). The benchmarking theory has been derived from Deming's four stages: plan, do, check and act, (Plan-Do-Check-Act cycle or Deming cycle) (Watson, 1992; Prabir, 2005; Ajelabi \& Tang, 2010), where numerous benchmarking process models have also been proposed by researchers both in industry and academia. Benchmarking method requires two parties; the bench marker and the bench markee, whereby the former is the organization carrying out a benchmarking procedure and the latter is the organization being benchmarked (Metin \& Kevin, 2001). APQC consortium benchmarking studies have also used a four-phased approach: planning, data collection, data analysis and reporting, and adaptations of study findings.

Planning Phase ( Plan) involves forming and training benchmarking team, identifying the area of focus and the critical success factors (CSF)s, establishing scope of the study, identifying targeted benchmarking partners and 
defining the data collection plan and determine how the data will be used or managed. Collection Phase (Do) involves evaluating results and identifying potential partners, developing data collection instruments and carrying out a pilot data collection instruments internally and lastly conducting detailed investigation using the detailed questionnaire, follow-up telephone interviews or site visits (Ajelabi \& Tang, 2010).

Analysis Phase (Check) entails comparing your current performance data to your partners' data to identify gaps, identifying operational best practices and enablers, that is what are participants doing that you are not doing and how do they do it (enablers), formulating strategy to close the gaps by assess adaptability of practices and finally develop implementation plan. Adapting Improvements Phase (Act) involves implementing the plan, monitoring and reporting the progress, communicating the results (internally and to benchmarking partners) and finally planning for continuous improvement (Ajelabi \& Tang, 2010).

\section{Research Methodology:-}

This study adopted a correlation research design. Correlation studies involves collecting data in order to determine whether and to what degree a relationship (correlation coefficient, $r$ ) exists between two or more quantifiable variables (Mugenda and Mugenda, 2003; Kothari, 2004; Mugenda, 2008). The target population comprised of school principals or deputy principals, directors of studies and the heads of departments in public secondary schools from the 22 public secondary schools in Keiyo Sub-County. The schools were then stratified into national \& extracounty, county and sub-county then a simple random sampling technique was used to select the required sample of schools from each of the strata.

This study generated data using majorly the questionnaires and personal interviews. Descriptive and inferential statistics were used to calculate, present and analyze the data.

\section{Findings:-}

Correlation analysis was conducted to determine the relationship between the variables using Pearson's product moment correlation coefficient analysis as shown Table 4.15. As cited in Zikmund et. al (2010), the correlation coefficient ranges from +1 to -1 and if $r$ equals to +1 then there exist a perfect positive relationship. If $r$ equals to -1 , then there exist a perfect negative relationship.

Table 4.15:-correlation analysis

\begin{tabular}{|c|c|c|}
\hline & & KCSE performance \\
\hline \multirow{3}{*}{$\begin{array}{l}\text { Planning of } \\
\text { benchmarking }\end{array}$} & Pearson Correlation & 0.384 \\
\hline & Sig. (2-tailed) & 0.021 \\
\hline & $\mathrm{N}$ & 60 \\
\hline \multirow[t]{3}{*}{ Data collection } & Pearson Correlation & 0.709 \\
\hline & Sig. (2-tailed) & 0.000 \\
\hline & $\mathrm{N}$ & 60 \\
\hline \multirow[t]{3}{*}{ Data analysis } & Pearson Correlation & 0.049 \\
\hline & Sig. (2-tailed) & 0.778 \\
\hline & $\mathrm{N}$ & 60 \\
\hline \multirow{3}{*}{$\begin{array}{l}\text { Implementation of } \\
\text { benchmarking }\end{array}$} & Pearson Correlation & 0.590 \\
\hline & Sig. (2-tailed) & 0.000 \\
\hline & $\mathrm{N}$ & 60 \\
\hline
\end{tabular}

Planning of benchmarking had a positive correlation of 0.384 and the same was statistically significant to explain KCSE performance measurement as the p-value was 0.021 . Hence, the rejection of the null hypothesis that planning in benchmarking had no significant influence on performance of schools in KCSE and the alternative that planning in benchmarking has significance influence on performance of schools in KCSE was accepted.

Data collection had a strong positive correlation of 0.709 with performance of school in KCSE and is also statistically significant to explain the performance of school in KCSE as it had a p-value of 0.000 . Hence, the rejection of the null hypothesis that data collection in benchmarking has no significant influence on the performance 
of schools in KCSE and acceptance of the alternative one that data collection in benchmarking has a significant influence on the performance of schools in KCSE.

Data analysis stage of benchmarking has a weak positive correlation with performance of schools in KCSE $(\mathrm{r}=$ 0.049 ) but these results were not statistically significant with p-value being 0.778 . Thus, the research accepted the null hypothesis that data analysis step in benchmarking has no significant influence on the performance of schools in KCSE.

Implementation of benchmarking reports has positive correlation with the performance of schools in KCSE $(\mathrm{r}=0.590)$ and the same is statistically significant $(\mathrm{p}=0.000)$. The null hypothesis, 'implementation of benchmarking reports has no significant influence on performance of schools in KCSE' was rejected and the alternative one 'implementation of benchmarking reports has a significant influence on performance of schools in KCSE' was accepted.

\section{Planning in Benchmarking and the Performance of school in KCSE}

The most common type of benchmarking practiced in schools is the external benchmarking with $66.7 \%$ respondents acknowledging to have adopted it while the least practiced is the internal benchmarking with $10.0 \%$ of the response. It is also clear that most schools have gone into the benchmarking practice because of the need to improve the school academic performance in KCSE. This is greatly influencing the decision/need to benchmark with 50\% of respondents giving a very great extent rating. This concurs with the study findings by Nyaoga et al. (2013) where they found out that most schools value benchmarking as a tool for competitiveness in pursuit of better academic performance. It is also a reason why most of the respondents acknowledged that the academic performance is a factor to be considered when choosing the benchmarking partner. Reid (2008) explained benchmarking as comparison with the best-in-class and from the study outcome, most schools do benchmark from schools with equal entry behavior of learners and those in same school category that is national, county and sub-county.

Benchmarking is conducted by teams consisting of individuals with direct operational experience and knowledge of the process (Camp, 1995). Members should possess analytical, research, process documentation, and team facilitation skills. From the study findings, schools form benchmarking teams consisting of head of subjects (HOSs) and head of departments (HODs). These groups are considered to have a better understand of the operations within their departments and can identify the practices that need to be adopted for better performance.

Planning of benchmarking is seen to have influenced the academic performance in schools. Planning activities which include: proper selection of the benchmarking partner and identification of key areas to benchmark greatly influence performance of schools in KCSE with $61.7 \%$ and $51.3 \%$ of the respondents agreeing to the two respectively. This meant that who to benchmark and what to benchmark are key to benchmarking in relation to academic performance. Schools have opted to benchmark on schools that are performing better than them echoing Achama \& Nwogu (2013) study on public schools benchmarking on performing private schools. It is also clear that during planning, schools needed to define their data collection plan and tools to use to collect information from the identified areas. 55.0\% of the respondents agreed to this that it greatly influences KCSE performance in schools. Andersen \& Pettersen (1996) in their description of benchmarking process concluded that planning of benchmarking consumes $50 \%$ of the time and schools have also laid emphasis on this. Training of the benchmarking team is another planning activity that affects KCSE performance though most respondents $(35.0 \%)$ were neutral about it.

\section{Data Collection in Benchmarking and the Performance of school in KCSE}

During the data collection stage, schools used several methods to aid them in collecting relevant details from the benchmarks. The methods frequently employed were use of questionnaires and personal interviews with $35.0 \%$ and $20.0 \%$ response respectively. The least practiced was the use of video recording.

In many instances, lack of preparation has seen many bench markers come back from the site visits empty handed (Prabir, 1996). The extent to which the data collection in benchmarking is done well is also dependent on several factors and these factors also influence the school performance in KCSE exams. For example, openness and acceptance by the benchmarking partner has the greatest influence on performance and this had $73.3 \%$ of the respondents accepting so. Acceptance by the benchmarkee gives the bench marker adequate interaction time to obtain relevant information and to visit all the relevant departments. $72.0 \%$ of the respondents did agree on this. 
$35.0 \%$ of the respondents identified a successful data collection is also dependent on the effectiveness of the benchmarking team and this affected performance of school to a significant extent.

A team is therefore the work horse of benchmarking (Prabir, 1996). The effectiveness of the benchmarking team included aspects such as how well they are trained, their size and the understanding of the process. An effective team can identify key success factors in the benchmarked school based on the objectives and there after match this to their own.

Data analysis in benchmarking and the Performance of school in KCSE

Schools do carry out data analysis $(81.7 \%)$ of the data collected during benchmarking. The HODs and HOSs are the major participants in the data analysis process. This study also showed that most schools benchmarked on schools that had scored average mean score of between 8.5-11.0 and those who had benchmarked had improved their mean score performance to above 6.2 from as low as 5.0 from 2010-2014. This is an improvement of +0.7 which concurs with Amunga et al. (2013) who found out that schools that practiced benchmarking had an improvement of +0.6 (from 5.5 to 6.1). The study also showed great difference when schools incorporated benchmarking with another improvement tool such as collaboration and they attained a mean score of 8.480 in KCSE.

In Ambala's (2006) study it was also established improvement from 5.633 to $6.379(+0.746)$ in the KCSE mean scores with the practice of benchmarking. Benchmarking is therefore a performance improvement tool in most schools but its contribution is not as high as when used together with another performance improvement tool. It is also clear that schools which have carried out benchmarking did it on those schools that have had better performance than them.

The current study further identified some of the challenges experienced at the time of data analysis which included; absenteeism of some team members at time of analysis, some schools didn't revealed their techniques to good performance, some obtained scanty information, while a small percentage said cost of benchmarking was too high and inadequacy of time also was a problem.

Implementation of benchmarking reports and the Performance of school in KCSE

Most schools had carried out implementation of their benchmarking reports. On average $(78.17 \%)$ of respondents acknowledged that their schools developed implementation plans with the process being spearheaded by the respective HODs in the subject areas while $21.83 \%$ said that there were no implementation plans in all the subject areas.

The study further asked the extent to which implementation of various benchmarks in their schools had contributed to improved performance of KCSE. Creation of extra learning time and improvement of the staff welfare are examples of the benchmarks that have significantly influenced the performance of schools in KCSE. Most of the respondents (over 50.0\%) rated the two as having influenced their school's performance to a great extent. More time is spent on close monitoring of weaker learners and sufficient/early syllabus coverage enabling more time for revision. Some principals mentioned that schools have always cleared the four year secondary school syllabus in a record time of three years. The extra activities have been pegged on effective and better teacher motivation strategies implemented by these schools.

Response on adoption of new evaluation system (examination), change in the staff and student motivational system and collaboration with other schools for example having joint exams, programs and many others, have had moderate influence on the level performance in this schools. Staff orientation on new changes was also one of the benchmarks implemented but has had minimal contribution to the improvement of KCSE performance. These findings concurred with those of Amunga et al. (2013) assertion that there is a significant difference in secondary schools' mean scores as a result of collaboration and benchmarking.

Study findings on the stages of benchmarking process as outlined in the Deming's PDCA model of benchmarking showed that planning is mainly carried out by school management, HODs and teachers while data collection is done by teachers and HODs. Data analysis mainly involves the management, HODs and the respective teachers with implementation being spearheaded by management and also involves the HODs, BOM/PTA and teachers. 
Benchmarking practice can also be enhanced by several factors so that its objectives are forthcoming. Findings on the factors that can enhance benchmarking practices showed that the level of performance or productivity expected (targeted mean) after the benchmarking greatly enhances benchmarking practices with $81.3 \%$ of the respondents agreeing to this. Benchmarking majorly involves change where one is likely to adopt new techniques of operation (Prabir 1995; Margarita 2004) thus the school's general openness to change and willingness to take risks greatly enhance the practice. This is so as $83.4 \%$ of the respondents agreed to this factor. The implementation of the benchmarks also requires general support and cooperation among the staff members so as the benchmarking objective is attained. $86.7 \%$ of the respondents accept that there should be staff cooperation for effective benchmarking while $46.7 \%$ strongly agree that monitoring need to be done to determine the extent to which benchmarks have been implemented. It is also advisable that benchmarking can be done frequently as it will encourage continuous learning on new practices that can enhance performance.

This study further identified the challenges faced by schools during benchmarking. Top management commitment is a major challenge facing benchmarking in public secondary schools in Keiyo sub-county and $90.0 \%$ of the respondents acknowledged it. Resource availability is another challenge where schools don't have enough finance to facilitate implementation of the identified benchmarks while in other situations, school managements have not been willing to provide enough resources towards the exercise. Elmuti \& Kathawala, (1997) concluded that management should be committed in communicating and implementing benchmarking reports. The management should therefore provide resources for benchmarking, plan well and even train/orient the participating staff on the process, be able to identify the key areas to benchmark and plan on how implementation will be executed in order to bring everyone on board and avoid resistance.

Other challenges identified were; - difficulty/imbalance in formation of benchmarking teams, failure to plan and identify key areas to benchmark and resistance to change on new methods of operation. Elmuti \& Kathawala (1997) affirms that with new changes, there will always be some employees reluctant to get involved and cooperate with new policies. The success of implementation of a benchmarking system relies on employees performing with the view of meeting the set objectives (Suhaiza et al., 2008). These findings are in line with the findings of Magutu et al., (2011) that indicated most critical factors facing benchmarking processes in Kenya as; time and resource availability, limited duration, and comparability and compatibility issues. Benchmarking therefore requires significant resources in terms of time, money and people (Margarita, 2004).

\section{Interpretation of research findings}

Achama \& Nwogu, (2013) commented that the practice of benchmarking in educational institution has therefore been necessitated by the demand for good performance and effective utilization of resources. Schools choose to benchmark from schools with better academic and the ones they belief they admit learners of similar ability and fall in the same category (national, county, sub-county). The need for improve performance in public secondary schools calls for benchmarking thus making benchmarking visionary or goal oriented.

Proper preparation and planning for the benchmarking process by a school will eventually contribute to a significant improvement in its performance in KCSE exams. Factors related to planning such as proper selection of the benchmarking partner, selection and training of the benchmarking team, and identification of the key areas to benchmark greatly influences performance of schools in KCSE. This is attributed to best practices identified from the right partner and how effective this information will be collected. This means that choosing the right benchmarking team and training increases their effectiveness thus contributing to collection of right information. The best practices can therefore be implemented later to bring improved performance in schools. This justifies the positive correlation between planning of benchmarking and performance of schools in KCSE exams.

The extent to which data collection in benchmarking is undertaken greatly influences the school performance in KCSE exams. Factors such as duration of the interaction time, ability to visit all the relevant departments in the school benchmarked, data collection method used and, openness and acceptance by the partner (school benchmarked), has greatly influenced performance of schools in KCSE exams. This is because these factors determine the amount of information (performance indicators) obtained during the study that can enhance greater performance. Hence, that data collection forms the backbone of benchmarking for better performance, justifying the strong positive correlation of 0.709 with school performance KCSE exams. The relationship is statistically significant with a $p$ value of 0.000 . 
Data analysis in benchmarking had a weak positive correlation ( $\mathrm{r}=0.049)$ with performance of schools in KCSE exams. The reason for this is that most schools did put much emphasis on the analysis as most "best practices" identified from the benchmarked well performing schools were adopted wholesomely with the perception that it will fit into their systems. This explains why the study shows that data analysis is insignificant $(\mathrm{p}=0.778)$ in explaining performance of schools in KCSE. Data analysis also faces numerous challenges which include; absenteeism of some team members during analysis, some obtained scanty information and inadequacy of time. Since the step is also overlooked, it was also noted that few schools lacked a well-designed analysis plan while others delayed the analysis after data collection resulting in shallow analysis.

Implementation of benchmarks such creation of extra learning time and improvement of the staff welfare greatly influences the performance of schools in KCSE. Creation of the extra learning time has enabled early completion of the syllabus with schools getting enough time for revision. Thus, Implementation of benchmarking reports has a strong and positive correlation with school performance in KCSE $(r=0.590, \mathrm{p}=0.000)$. Other benchmarks that have been implemented and are associated with better results were; adoption of new evaluation system (examination), improved staff welfare, collaboration with other schools for example having joint exams programs and staff orientation on new changes.

\section{Conclusions and recommendations:- \\ Conclusions}

This study concludes that; the commonly practiced type of benchmarking in public secondary schools is external benchmarking with the identified top performers. Benchmarking process carried out in public secondary schools is based on the Deming's PDCA cycle of benchmarking with an aim of improving performance in KCSE exams.

Planning of benchmarking, data collection and implementation of the benchmarking reports stages have been done adequately by the public secondary schools and this can significantly explain the performance of these schools in KCSE. Data analysis is not well executed as this step has been constantly overlooked in most schools with implementation of benchmarking reports done without any analysis. Numerous challenges are experienced at this step which include; absenteeism of team members during analysis, lack of a well-designed analysis plan and inadequate time set for analysis. Despite the achievements from benchmarking, several challenges have experienced during process which included; lack of top level management commitment, resource unavailability, difficulty in formation of benchmarking teams, planning and identification of key areas to benchmark and resistance to change.

\section{Recommendations}

Based on the findings and conclusion this study recommends that: schools to fully adopt the use of Deming's PDCA cycle model of benchmarking when carrying out benchmarking with other schools/institutions, Schools should carry out data analysis in benchmarking properly and exhaustively so as to identify what is best for them to adopt into their system and this will eliminate the practice of shallow analysis and wholesome adoption. Schools should also design follow-up mechanism to monitor the benchmarks implemented and take corrective measures in case of any deviations.

The study further recommends that internal benchmarking should be practiced in schools on the departments that are doing well in KCSE performance rather than embracing the external benchmarking all through which is rather expensive. Finally, the Ministry of Education should come up with a formal structure of benchmarking, which could assist school managers to systematically and continuously adopt best practices from high performing schools. This will eventually lead to improved performance of schools in national examinations.

\section{Areas of Further Research}

This study proposes for a similar study conducted in other parts of the country would be useful for comparative purposes. Indeed, a nationwide study would be useful for comparing the results from the various regions in the country. The study was also limited in terms of context where it only focused on the application of Deming's cycle model of benchmarking and performance of public secondary schools in KCSE. For further research, there is need to consider a study on private secondary schools and also other sectors beyond the education sector.

In terms of concepts, the current study only focused on benchmarking process and its influence on academic performance. However, academic performance can be influenced by other factors such as learners' discipline, 
resources availability, administrative set-up and parental support, and quality of internal supervision among many others. Research on the influence of these factors on academic performance should also be done.

\section{References:-}

1. Achama, M. C., \& Nwogu, U. J. (2013). Benchmarking For Improvement of Quality in Private Universal Basic Education Junior Secondary Schools in Rivers State'. Journal of Education and Practice, 4(5).

2. Ajelabi, I. \& Tang, Y. (2010). The Adoption of Benchmarking Principles for Project Management Performance Improvement. International Journal of Managing Public Sector Information and Communication Technologies (IJMPICT). Vol. 1.

3. American Productivity and Quality Center (1993). 'Basics of Benchmarking' APQC, Houston, Texas. Financial $\begin{array}{lllll}\text { benchmarking } & \text { article } & \text { Updated: } & 26 & \text { April }\end{array}$ http://www.education.gov.uk/schools/adminandfinance/financialmanagem ent/a00 14737/ financialbenchmarking retrieved on 03/10/2014

4. Ambula, R. L. (2006). Benchmarking in public secondary schools in Nairobi Province: Kenya Information Preservation Society. Nairobi.

5. Andersen, B. \& Pettersen, P.G. (1996). The Benchmarking Handbook: Step-by-Step Instructions. Chapman \& Hall, London.

6. Amunga, J., Ondigi, B., Ndiku, J., \& Ochieng, P. (2013).Collaboration, benchmarking and secondary schools' mean scores in the Western region, Kenya: An analytical investigation. International Journal of Education and Research 1(9).

7. Barney, J.B. (1991). Firm resources and sustained competitive advantage. Journal of Management 17(1), pp 99120.

8. Camp, R.C. (2006) Benchmarking: The Search for Industry Best Practices That Lead to Superior Performance. Productivity Press, Milwaukee.

9. Camp, R. C. (1995). Business Process Benchmarking: Finding and Implementing Best Practices. American Society for Quality, U.S.A.

10. Deros, B., Tan J., Rahman, N.A \& Daud, N.A. (2011). An Effective Approach for Benchmarking Implementation. American J. of Engineering and Applied Sciences 4 (2): 288-293, Science Publications

11. Dervitsiotis, K., N. (2000). Benchmarking and business paradigm shifts: Total Quality Management. Vol 11:641-646.

12. Douglas, W. \& Neil, A. (2005). Benchmarking Marketing Capabilities for Sustainable Advantage. Journal of Marketing. 69(1):80.http://dx.doi./g/10.1509/jmkg.69.1.80.55505

13. Elmuti, D. \& Kathawala, Y. (1997). An overview of benchmarking process: a tool for continuous improvement and competitive advantage. Benchmarking for QualityManagement \& Technology. 4(4):229-243.

14. Gunasekaran, A. (2002) "Benchmarking in education", Benchmarking: An International Journal.9 (1).http://www.emeraldinsight.com/journals.htm?articleid=1485830\&show=html-2245hrs, $\quad$ retrieved $\quad$ on $01 / 11 / 2014$

15. Keiyo Sub-county Education report of 2014

16. Margarita, I. (2004). Benchmarking methodology in a transport sector http://dx.doi./g/10.1080/16484142.2004.9637986 retrieved on 30/01/2014.

17. Magutu, O. P., Mbeche, M. I., Nyamwange, O. S., \& Nyaoga, B. R. (2011). A survey of benchmarking practices in higher education in Kenya: The case of public universities. IBIMA Business Review, Vol 2011, Article ID 357694.

18. Metin, K. \& Kevin, N. (2001). An Overview of Benchmarking Literature. Journal of Quality Assurance in Hospitality \& Tourism, 2:3-4, 7-23, DOI:10.1300/J162v02n03_02 retrieved on 30/01/2014.

19. Mugenda, M.O \& Mugenda, G.A (2003). Research Methods: Quantitative and Qualitative Approach. Acts Press: Kenya.

20. Mugenda, G.A (2008). Social Science Research: Theory and Principles. Kijabe Printing Press: Kenya.

21. Nunnally, J.C. \& Bernstein, I.H. (1994). Psychometric Theory (3rd ed.). New York: McGraw-Hill

22. Nyaoga, B R., Mundia, M. C., \& Riungu, I. (2013). "The effect of Benchmarking on performance in Secondary Schools in Nakuru Municipality." International Journal of Management, IT and Engineering (IJMIE). 3(2).

23. Ongeri, D.K., Nyaoga, B.R., Bosire, M.R. \& Nyambega, E. (2014). "A Survey of Performance Improvement through benchmarking in Commercial Banks in Kenya: The Managers' Perception and Experience". International Journal of Businessand Economics Research. 3(1):6-14. doi:10.11648/j.ijber.20140301.12

24. Prabir K.B (1996). "Role of benchmarking as a competitive strategy: the logistics experience.'International Journal of Physical Distribution \& Logistics Management. 26(2):4-22. MCB University Press, 0960-0035. 
25. Reid, K. (2008). Gaining a Competitive Advantage Using Benchmarking. http://www.pcimag.com/articles/gaining-a-competitive-advantage-using- benchmarking retrieved on 05/06/2014,5.06pm

26. Rumelt, R. (1987). The Competitive Challenge, Ballinger, Cambridge. Rumelt, R. 1984. Toward a strategic theory of the firm. In Competitive StrategicManagement, pp. 556-570. Lamb R. (ed.). Prentice-Hall: Englewood Cliffs, New Jersey.

27. Suhaiza Z., Tutik A and Yudi Fe. (2008, October) Factors influencing the effectiveness of benchmarking practice among manufacturing companies in Indonesia. 8th Global Conference on Business \& Economics. October 18-19th, 2008. Florence, Italy. ISBN: 978-0-9742114-5-9.

28. Truijens, O. (2003). "A Critical Review of the Resource-based View of the Firm," University of Amsterdam, Netherlands. Sprouts: Working Papers on Information Systems, 3(6). http://sprouts.aisnet./g/3-6.

29. Watson, G.H. (1992). The Benchmarking Workbook: Adapting Best Practices for Performance Improvement. Productivity Press. Cambridge.

30. Yasar, F. J. \& Zairi, M. (2001).Future trends in benchmarking for competitive advantage: A global survey, Total Quality Management, 12:7-8, 906-912, DOI:10.1080/09544120100000014.http://dx.doi./g/10.1080/09544120100000014 retrieved on 30/01/2014.

31. Zairi, M. (1996). Benchmarking for Best Practice: Continuous Learning through Sustainable Innovation. Butterworth-Heinemann. Oxford.

32. Zikmund, et. al. (2010). Business Research Methods. 8th ed. South-Western Gate Australia. 